\section{Comparison of cupulometric and psychophysical thresholds for perception of rotation and the oculogyral illusion*}

\author{
STEVEN L. DOCKSTADER $\dagger$ \\ San Jose State College, San Jose, California 951-
}

The purpose of this study was to compare thresholds for angular acceleration derived by subjective cupulometry and by a staircase method. Thresholds for the perception of rotation and the oculogyral illusion were determined for 10 Os who were rotated about their vertical axis. The cupulometric thresholds were significantly higher, more variable, and not predictable from the staircase thresholds. Furthermore, cupulometry failed to distinguish between the thresholds for the perception of rotation and the oculogyral illusion, although both indicators functioned according to the prediction of the underlying linear model. Individual differences supported the general conclusion that cupulometric thresholds bear no relationship to the sensory threshold derived in a classical psychophysical manner.

Cupulograms have been extensively used in clinical otolaryngology to provide information regarding the functioning of the vestibular apparatus. As defined by van Egmond and others, cupulograms are plots of the duration of aftereffects of sudden deceleration against the common logarithm of the velocity just prior to an impulsive stop using a brake (van Egmond, Groen, \& Jongkees, 1949; Mann \& Canella, 1956). Each deceleration was preceded by a "subliminal impulse" over a prolonged period to attain the appropriate velocity. By a convention initiated by van Egmond et al, the deceleration took place on the average within about $2 \mathrm{sec}$ following rotation to the right or left. The decelerative stimulus was thus defined in terms of an easily measured velocity rather than in terms of a specified positive or negative acceleration acting over a known period of time.

Some investigators have also extrapolated these plots to zero duration of the aftereffect to derive what is called a "threshold" for the perception of rotation (van Egmond et al, 1949). Such a procedure is open to question on several grounds, but no data have been found which compare cupulometric thresholds with regular psychophysical thresholds. It was the purpose of this study to make such a comparison for both the oculogyral ilusion (OGI) and the perception of rotation (POR). Furthermore, the device used to rotate the $O s$ made it possible to

*This study was carried out at Ames Research Center, Moffet Field, California, under National Aeronautics and Space Administration Grant NGL-05-046-002 to San Jose State College.

+ Presently at Denver University. Correspondence may be directed to the aluthor, Department of Psychology, Denver University. Denver, Colorado 80210. present the accelerations at precisely known magnitudes and durations. Consequently, the stimulus level could be specified as an acceleration times time (velocity) rather than as a specific velocity reduced to zero by an unknown acceleration acting over an indeterminant time as in earlier studies. In addition, the prolonged "subthreshold pulse" to attain a desired velocity was not required since a given acceleration over time could be started at any velocity within the limits of the apparatus.

\section{Observers \\ METHOD \\ Ten men between the ages of 21 and 40} served as $O s$ in the present study. They were judged to be normal and healthy on a general physical examination, which included a hearing test and a caloric nystagmus test of vestibular functioning. The 10-sec duration POR and OGI thresholds subsequently determined for the Os were well within the normal range (Clark \& Stewart, 1969).

\section{Apparatus}

The Os were rotated about their vertical axes in the Ames man-carrying rotation device (MCRD), which has been described in detail elsewhere (Clark \& Stewart, 1968a). The important characteristics of the MCRD for the present experiment are that it is free of significant vibrations and that the accelerations and decelerations can be presented within very small limits of error.

\section{Procedure}

Although the tasks differed between the psychophysical and the cupulometric method. there were common features to both. O sat erect at the center of rotation with his helmet pressed firmly back against a U-shaped headrest which maintained the head in a fixed position. All observations were made in the dark when the POR was being used as an indicator and with only ultraviolet light illuminating a cube when the OGI was used. Each test session lasted approximately $30 \mathrm{~min}$, and a minimum of $30 \mathrm{sec}$ elapsed between the end of one stimulus impulse and the beginning of the nexi. The duration of the stimulus was $2 \mathrm{sec}$ for the psychophysical method and 2 or $4 \mathrm{sec}$ for the cupulometric method. For each task, O was provided with practice trials during his first test session to familiarize himself with the procedure.

The forced-choice random double-staircase method. This threshold method was essentially a method of limits procedure involving a random walk about the threshold, the upper and lower limits of which were estimated during preliminary practice trials. A full description of the method, a comparison with other methods, and its evaluation as a psychophysical tool has been presented elsewhere (Clark \& Stewart, 1968b). For the present study, the only change in the procedure of Clark and Stewart was the use of 32 practice trials instead of 48 and the stimulus duration was $2 \mathrm{sec}$.

The cupulometric method. This followed the general procedure of van Egmond et al (1948). Their procedure involved rotating $O$ for a period at a constant velocity and then applying the break to provide the stimulus. Because their early apparatus did not produce reliable stopping times (varying between 0.5 and $3.0 \mathrm{sec}$ ), the magnitude and duration of the impulses were not accurately known. In the present study, however, stopping was not necessary for impulse presentation since "velocity" was defined precisely as an acceleration times time. This was possible because in the MCRD the magnitude and duration of stimuli are measured and controlled and are always known values. Not stopping had a potential advantage in that it would not influence $\mathrm{O}^{*} \mathrm{~s}$ judgment of the aftereffect by the knowledge that he was not rotating. Heeding the warning of Benson, Goorney, and Reason (1966), instructions given to Os were deliberately neutral in strength regarding the judgment of the endpoint of the aftereffcct.

Nine positive or negative acceleration (a) levels (Tablc 1 ) between 1 and $30 \mathrm{deg} / \mathrm{sec}^{2}$ were used, eacl being given five times. The trials were arranged in five blocks, each block containing all nine stimulus levels in random sequence. This made a total of 90 experimental trials for each 0,45 for $P O R$ and 45 for OGI. One practice session preceded the data collection and consisted 
Table 1

Magnitude and Duration of Acceleration and Intertrial Intervals for Cupulograms

\begin{tabular}{cccc}
\hline $\begin{array}{c}\text { Acceleration } \\
\text { (a) }\end{array}$ & $\begin{array}{c}\text { Duration } \\
\text { (t) }\end{array}$ & at & $\begin{array}{c}\text { Intertrial } \\
\text { Interval } \\
\text { (Sec) }\end{array}$ \\
\hline $1.0 \mathrm{deg} / \mathrm{sec}^{2}$ & 2 & $2 \mathrm{deg} / \mathrm{sec}$ & 60 \\
$1.5 \mathrm{deg} / \mathrm{sec}^{2}$ & 2 & $3 \mathrm{deg} / \mathrm{sec}$ & 60 \\
$2.5 \mathrm{deg} / \mathrm{sec}^{2}$ & 2 & $5 \mathrm{deg} / \mathrm{sec}$ & 60 \\
$5.0 \mathrm{deg} / \mathrm{sec}^{2}$ & 2 & $10 \mathrm{deg} / \mathrm{sec}$ & 60 \\
$10.0 \mathrm{deg} / \mathrm{sec}^{2}$ & 2 & $20 \mathrm{deg} / \mathrm{sec}$ & 120 \\
$20.0 \mathrm{deg} / \mathrm{sec}^{2}$ & 2 & $40 \mathrm{deg} / \mathrm{sec}$ & 120 \\
$30.0 \mathrm{deg} / \mathrm{sec}^{2}$ & 2 & $60 \mathrm{deg} / \mathrm{sec}$ & 120 \\
$22.5 \mathrm{deg} / \mathrm{sec}^{2}$ & 4 & $90 \mathrm{deg} / \mathrm{sec}$ & 150 \\
$30.0 \mathrm{deg} / \mathrm{sec}^{2}$ & 4 & $120 \mathrm{deg} / \mathrm{sec}$ & 150 \\
\hline
\end{tabular}

of one trial at each level of stimulation for both the POR and the OGI.

The intertrial interval varied systematically with the magnitude of the stimulus according to empirically derived rates of decay (Parsons, in press). The intertrial intervals and the length of the experimental sessions were strictly adhered to as minimal values in order to avoid the confounding effects of previous stimuli, response decline, and fatigue (Mann \& Canella, 1956; Cawthorne, Dix, Hallpike, \& Hood, 1956).

The task for $O$ was simply to signal the onset of perceived stimulation by giving its direction verbally, incorrect reports being scored as zero. This applied to the perceived direction of rotation during POR or to the perceived direction of the apparent movement of the cube during the first effect of the OGI. Then, when O no longer perceived these sensations, he verbally reported "stop." The duration of these periods was recorded to the nearest second by use of a stopwatch. Os were instructed to report only upon the first effects of stimulation; aftereffects were disregarded and generally did not occur except at higher magnitudes.

The order of data collection for the two methods and the two indicators was systematically arranged across sessions to control for possible order effects. For half the Os, cupulometric data were taken first, for the other half the staircase method was first. Within each of these groups the indicators, POR and OGI, were alternated across successive sessions, five having POR first.

\section{Threshold Comparisons}

The staircase thresholds were determined as the mean value of 30 pairs of trials. The cupulometric thresholds were determined as the point of intercept of the line of best fit of the five-level cupulograms $\left(5-60 \mathrm{deg} / \mathrm{sec}^{2}\right)$ with the acceleration $x$ time axis (i.e., where duration $=0$ ). The $a$ t value was then converted to accelcration by dividing this number by the duration.
The thresholds for POR and OGI determined by both methods are presented in Table 2. It can be seen that the thresholds produced by cupulometry were considerably higher than those of the staircase method. A t test of the significance of the difference between correlated means revealed that POR thresholds derived by the two methods were not different $[t(9)=1.93 ; \mathrm{p}<.10]$. However, if the aberrant value for 02 is unitted, there was clearly a significant difference to be found $[t(8)=4.79$; $\mathrm{p}<.01]$. The same results appear to hold for the thresholds of the OGI. As with POR, OGI thresholds by the cupulometric technique were significantly different from those produced by the staircase method on a two-tailed test of difference scores $[\mathrm{t}(9)=3.25 ; \mathrm{p}=.01]$.

It is clear that cupulometric thresholds for both POR and OGI are considerably higher than those derived by the staircase method. The proportion of thresholds exceeding $1 \mathrm{deg} / \mathrm{sec}^{2}$ for the cupulometric method was significantly larger than the proportion for the staircase method $\left[\chi^{2}(1)=7.11 ; p<.01\right]$

While it has generally been found that the OGI is a much more sensitive indicator of angular acceleration than the POR, the $t$ test of difference scores for the cupulometric thresholds was not significant $[\mathrm{t}(9)=1.94 ; \mathrm{p}<.10]$. This is to be contrasted with the significant differences between POR and OGI for the staircase method $[\mathrm{t}(9)=2.64 ; \mathrm{p}<.05]$

It has been found that normal men are very sensitive to angular acceleration, as indicated by their thresholds, and the results of the present study tend to indicate that the thresholds derived psychophysically are homogeneous relative to cupulometric thresholds. The F test of homogeneity of variance, intended for independent samples, was used for this comparison. F tests were performed on the variances of the thresholds produced by each method for each indicator. Each was found to be significant, indicating that the variances of thresholds produced by the two methods are heterogeneous. For the POR: $F(9 / 8)=9.85 ; p<.005$. Similarly, but more significant, for the OGI: $F(9 / 9)=2.450 ; p<.001$.

Insofar as the indicators of the perception of angular acceleration reflect an underlying communality, the communality should manifest itself in covariation amongst indicators. Linear correlations were calculated between POR and OGI for each method. The correlation for the staircase method was +.69 which was quite significant $(p<.02)$. For the cupulometric thresholds, however, the correlation +.28 was not significantly
Table 2

Cupulometric and Staircase Threshold Values (Deg/ $/ \mathrm{Sec}^{2}$ )

\begin{tabular}{|c|c|c|c|c|}
\hline & $\begin{array}{l}\text { Perception } \\
\text { of Cupulo- } \\
\text { metric }\end{array}$ & $\begin{array}{c}\text { Rotation } \\
\text { Stair- } \\
\text { case }\end{array}$ & $\begin{array}{l}\text { Oculogy- } \\
\text { ral Cupulo- } \\
\text { metric }\end{array}$ & $\begin{array}{l}\text { Illusion } \\
\text { Stair- } \\
\text { case }\end{array}$ \\
\hline 1 & 0.35 & 0.50 & 0.00 & 0.09 \\
\hline 2 & 1.77 & 3.21 & 0.86 & 0.51 \\
\hline 3 & 4.27 & 1.28 & 0.66 & 0.43 \\
\hline 4 & 1.57 & 0.63 & 0.34 & 0.24 \\
\hline 5 & 1.39 & 0.49 & 1.92 & 0.24 \\
\hline 6 & 1.50 & 0.48 & 1.04 & 0.31 \\
\hline 7 & 0.30 & 0.28 & 0.65 & 0.23 \\
\hline 8 & 2.58 & 0.42 & 2.35 & 0.28 \\
\hline 9 & 1.70 & 1.35 & 1.00 & 0.17 \\
\hline 10 & 1.27 & 0.60 & 0.85 & 0.13 \\
\hline Mean & 1.67 & 0.92 & 0.97 & 0.26 \\
\hline SD & 1.13 & 0.88 & 0.70 & 0.13 \\
\hline Varianc & ce 1.28 & 0.77 & 0.49 & 0.02 \\
\hline
\end{tabular}

different from zero. Furthermore, there were no significant correlations between the methods for the indicators.

The Linear Relationship Between the Log of the Impulse and the Duration of the Aftereffects

The mean cupulograms for the 100 s are presented in Fig. 1. It is apparent that there is a linear trend for the central five points prescribed by the developers of the method. This appears to be the case for both POR and OGI. Examining the function for nine levels, it appears that it is linear for its entirety as the torsion pendulum model of vestibular functioning predicts. A statistical examination of the two mean cupulograms was performed. The results of the linear trend analysis for a repeated-measures design (Myers, 1966) indicate the indisputable presence of a linear component. The linear components for the POR and OGI were highly significant $[F(1 / 72)=74.81$ and 51.23 , respectively; $p<.001]$, as were the deviations from linearity in both cases $[F(7 / 72)=69.33$ and $46.49 ; p<.001]$.

The slope of the least-squares regression line for the cupulograms of Fig. 1 are both near the value of the normal cupulogram, which is 7.0 (Hulk \& Jongkees, 1948). It has usually been the case, however, that the slope for the OGI has been less steep, intercepting the abscissa at a lower value (van Dishoeck, Spoor, \& Nijhoff, 1954). This is not as evident a finding in the present study; the least-squares lines crossed near the upper end of the continuum approximately the same place as did the cupulograms of Fig. 1.

A visual examination would suggest that, with regard to slope, there are no significant differences between POR and OGI. A 2 by 9 randomized block analysis of variance was performed to determine if there was a significant difference between the means which compose the cupulograms of Fig. 1. It was found that there was no 


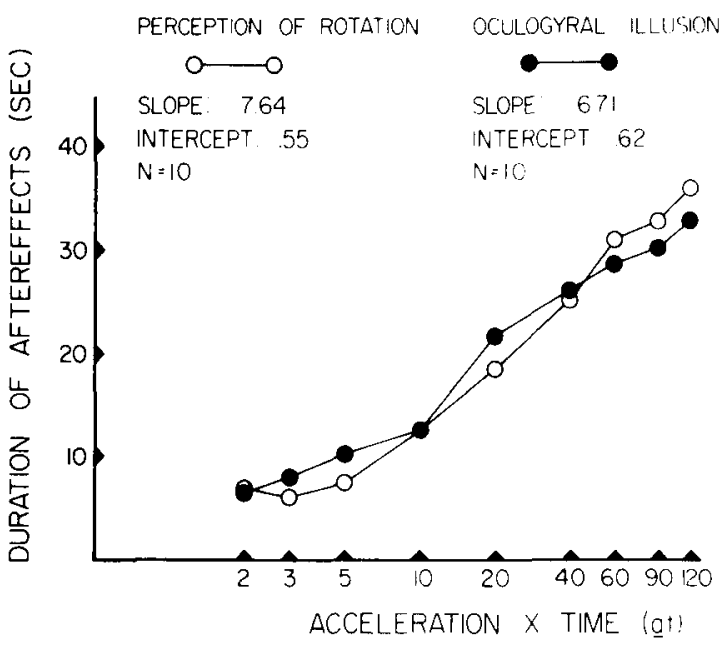

Fig. 1. Comparison of mean cupulograms for the perception of rotation and the oculogyral illusion.

significant difference between POR and OGI with regard to the duration of their persistence following an impulse of angular acceleration $(F<1.0)$. This is consistent with the findings of Reason and Benson (1968), who reported high crossmodal correlations for the persistence of the aftereffects of exponentially decaying sensations. For the present data, the correlation between the durations of POR and OGI for the mean cupulograms of Fig. 1 was greater than +.90 , which is highly significant even for $\mathrm{N}=9$.

\section{DISCUSSION}

Comparison of Cupulometric and Psychophysical Thresholds

The findings of the present study lead to the obvious conclusion that cupulometric thresholds are not comparable to thresholds derived by the staircase method. This is true for both POR and OGI. The inability of the cupulometric technique to predict staircase thresholds is a function, in part at least, of their variability. This extreme variability speaks strongly against the use of cupulometry in vestibular psychophysics. However, it is hardly surprising that cupulometry, a method using stimuli well above the psychophysical threshold, would produce thresholds which are not comparable to the staircase method.

It is noteworthy that cupulometric thresholds were found to be significantly higher than staircase thresholds. Doty (1969) has shown, using the staircase method, that the threshold is an inverse function of the duration of angular acceleration. Consequently. the short (2-sec) durations used in this study would be expected to produce thresholds which would be higher than those for optimum stimulus durations. Consequently, the differences reported above are biased in favor of the null hypothesis and strengthen the evidence that cupulometric thresholds are unrelated to staircase thresholds.

The finding of no significant difference between the intercepts of POR and OGI is contrary to earlier findings (van Dishoeck et al, 1954; Benson, 1965), but the small difference is in the direction of earlier findings. Similarly, the finding of a significant correlation between the POR and OGI thresholds is contrary to earlier data. This may be related to the duration of the stimulus, which is shorter than those used in earlier studies. However, the small number of $\mathrm{Os}$ in the present study limits the possible generalizations.

\section{The Linear Model}

Examination of the curves (Fig. 1) makes it clear that there is a linear relationship between the log of $a t$ and the duration of the aftereffects. particularly from at 5 to 60 . The tendency for the curves to level off at the lower levels, the "hockey stick cffect" (Dobie, 1969), is characteristic of many individual cupulograms. These results demonstrate that the developers of cupulometry (van tgmond et al. 1949) established acceleration limits which effectively reduced the "hockey stick effect." There also appears to be a break in the curves at about at of 60 , and it would appear that higher values were also eliminated 10 maintain the linear relationship.

\section{Individual Differences}

The average curves show clearly defined trends. but since cupulometry has been widely used clinically, an analysis of individual differences is particularly significant. Hulk and Jongkees (1948) describe the normal cupulogram as having a

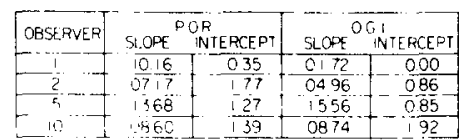

$\longrightarrow$ oculograt il $\longrightarrow$ usion $\sim$ PERCF PTION OF ROTATION

Fig. 2. Cupulograms of four Os.

slope varying from 4 to 16 , with an average of 7 , while the range of intercepts was 0.8 to $5.0 \mathrm{deg} / \mathrm{sec}$. These intercepts could be roughly estimated to have acceleration values from 0.40 to $2.5 \mathrm{deg} / \mathrm{sec}^{2}$.

The great variability between $O s$ in cupulograms is illustrated in Fig. 2.0 10 is the only example from the 10 Os to fit the description of "normality" reported by the originators of the method. The slopes are similar, the intercepts are about average, and the OGl curve is above the POR curve. It is noteworthy that this $O$ is the only one who did not show overlapping between the two curves. Such overlapping can be explained, in part at least, by the variability of the method, but no doubt the critical factor is the similarity of the two functions.

\section{REFERENCES}

BENSON, A. J. Spatial disorientation in flight. In J. A. Gillies (Ed.), A textbook of avaiation physiologv. London: Pergamon Press, 1965. BE.NSON, A. J., GOORNEY, A. B., \& REASON, J. T. The effects of instructions upon post-rotational sensations and nystagmus. Acta Oto-laryngologica, 1966, 62, 442-452.

(AWTHORNE, T., DIX, M. R., HALLPIKE, C. S. \& HOOD. J. D. The investigation of vestibular function. British Medical Bulletin, $1956,12,131-142$.

CLARK, B., \& STEWART, J. D. Comparison of sensitivity for the perception of bodily rotation and the oculogyral illusion. Perception \& Psychophysics. 1968a, 3, 253-256.

CLARK, B., \& STEWART, J. D. Comparison of three methods to determine thresholds for the perception of passive bodily anular acceleration. American Journal of Psychology, 1968b, 81, 207-216.

CLARK, B., \& STEWART, J. D. Effects of angular acceleration on man: Thresholds for the perception of rotation and the oculogyral illusion. Aerospace Medicine. 1969, 40 , 952-956. 
DOBIE, T. G, An evaluation of subjective cupulometry as a selection technique for use with potential aircrew trainess. Paper presented at the meetings of the Aerospace Medical Association, San Francisco, May 1969.

DOTY, R. L. The effect of duration of stimulus presentation upon the angular acceleration thresholds of man. Journal of Experimental Psychology, 1969, 80, 317-321.

HULK, J., \& JONGKEES, L. B. W. The turning test with small regulable stimuli: II. The normal cupulogram. Journal of Laryngology and Otology, 1948, 62, 70-75.

MANN, C. W., \& CANELLA, C. J. An examination of the technique of cupulometry. Pensacola, Florida: Tulane University-U.S.
Naval School of Aviation Medicine Joint Project Report No. 42, 1956.

MYERS, J. L. Fundamentals of experimental design. Boston: Allyn and Bacon, 1966.

PARSONS, R. D. Magnitude estimates of the oculogyral illusion during and following angular acceleration. Journal of Experimental Psychology, in press.

REASON, J. T., \& BENSON, A. J. Individual differences in the reported persistence of visual and labyrinthine aftersensations, and of exponentially decaying visual and auditory signals. British Journal of Psychology, 1968 , $59,167-172$.

van DISHOECK, H. A. E., SPOOR, A., \& NIJHOFF, P. The optogyral illusion and its relation to the nystagmus of the eyes. Acta Oto-laryngologica, 1954, 44, 597-607.

van EGMOND, A. A. J., GROEN, J. J., \& JONGKEES, L. B. W. The turning test with small reguiable stimuli: 1 . Method of examination: Cupulometria. Journal of Laryngology \& Otology, 1948, 62, 63-69.

van LGMOND, A. A. J., GROEN, J. J., \& JONGKEES, L. B. W. The mechanics of the semicircular canal. Journal of Physiology, $1949,110,1-17$.

(Accepted for publication July 20, 1970.) 